\title{
Clinical Significance of Rapid and Sensitive Quantification of Pseudomonas aeruginosa by Quantitative Reverse Transcription PCR Targeting of rRNA Molecules
}

\section{Mai Niikura ( $\sim$ mai-niikura@yakult.co.jp )}

Yakult Central Institute, Yakult Honsha Co., Ltd. https://orcid.org/0000-0002-9222-1753

\section{Satomi Atobe}

Yakult Central Institute, Yakult Honsha Co., Ltd.

Akira Takahashi

Yakult Central Institute, Yakult Honsha Co., Ltd.

\section{Yukiko Kado}

Yakult Central Institute, Yakult Honsha Co., Ltd.

\section{Takuya Sugimoto}

Yakult Central Institute, Yakult Honsha Co., Ltd.

Hirokazu Tsuji

Yakult Central Institute, Yakult Honsha Co., Ltd.

\section{Kentaro Shimizu}

Osaka University

\section{Hiroshi Ogura}

Osaka University

\section{Takashi Asahara}

Yakult Central Institute, Yakult Honsha Co., Ltd.

\section{Research}

Keywords: Pseudomonas aeruginosa, Infection, qRT-PCR, Quantification, Blood, Feces, ICU patients, Antimicrobial resistance, Microbiota

Posted Date: August 20th, 2020

DOl: https://doi.org/10.21203/rs.3.rs-61576/v1

License: (9) This work is licensed under a Creative Commons Attribution 4.0 International License. Read Full License 


\section{Abstract}

Background: For Pseudomonas aeruginosa, nosocomial infection control and appropriate antimicrobial treatment have become important issues. Diagnosis is critical in managing $P$. aeruginosa infection, but conventional methods are not highly accurate or rapid. A novel $P$. aeruginosa quantification system based on 23 S rRNA-targeted quantitative reverse transcription PCR (qRT-PCR) is a candidate diagnostic tool for managing $P$. aeruginosa infection. Here, we assessed the performance and potential impact of qRT-PCR on antibiotic therapy administered to ICU patients.

Methods: We first evaluated specificity and detection sensitivity of the 23S rRNA-targeted qRT-PCR system in vitro and determined whether $P$. aeruginosa viable counts detected by this system reflect the inflammatory response of infected cells. Next, we utilized this system on fecal samples collected from 65 septic ICU patients and 44 healthy volunteers to identify the ICU infection status. Additionally, we monitored drug-resistant $P$. aeruginosa in 4 ICU patients. The trend was compared with trends in fecal microbiota composition, antibiotic use, and mechanical ventilator use.

Results: The 23S rRNA-targeted qRT-PCR system quantified $P$. aeruginosa directly from clinical samples with high sensitivity (blood, $1 \mathrm{cell} / \mathrm{mL}$; stool, 100 cells $/ g$ ) without cross-reaction (within $6 \mathrm{~h}$ ). Additionally, $P$. aeruginosa numbers detected under antibacterial treatment correlated well with the inflammatory response compared to other detection methods such as culturing and qPCR. Using this system, we confirmed that the $P$. aeruginosa detection ratio in ICU patients was significantly higher than that in healthy volunteers $(49.2 \%$ vs. $13.6 \%, P<0.05)$. While some ICU patients had high $P$. aeruginosa numbers in feces $\left(10^{8}\right.$ cells $/ g$ of feces), some patients had very low $P$. aeruginosa numbers $\left(10^{2}\right.$ cells $/ \mathrm{g}$ of feces) as observed in healthy volunteers. $P$. aeruginosa counts in feces of ICU patients monitored by this system correlated negatively with the proportion of total obligate anaerobes and positively with facultative anaerobes and aerobes. Additionally, trends in $P$. aeruginosa counts accurately reflected various treatment backgrounds of ICU patients.

Conclusion: Our results suggest that this new 23S rRNA-targeted qRT-PCR system is beneficial for early diagnosis and evaluation of appropriate antibacterial treatment and may be a useful tool in combating $P$. aeruginosa infection.

\section{Background}

Pseudomonas aeruginosa, a ubiquitous bacterial species found in a wide variety of environmental settings, causes nosocomial pneumonia [1, 2], urinary tract infections [3], surgical site infections [4], and bloodstream infections [5], particularly in compromised patients with serious underlying medical conditions [6]. It is also known that the $P$. aeruginosa infections can be critical, with high mortality in cases of ventilator-associated pneumonia [2] or bacteremia [7, 8].

Recently, the prevalence of multidrug-resistant $P$. aeruginosa (MDRP), i.e. strains that are resistant to antibiotics such as fluoroquinolones, carbapenems, and aminoglycosides, which were previously 
effective for treating $P$. aeruginosa infections, has become a serious problem $[9,10]$. This resistance in $P$. aeruginosa is attributed to a variety of mechanisms, including the production of antibiotic-inactivating enzymes such as cephalosporinases, the constitutive expression of various efflux pumps, and the low permeability of the outer membrane [11]. Consequently, infection with MDRP strains can limit antibiotic therapy, resulting in inappropriate empirical therapy or delays in initiating appropriate therapy, which can lead to high mortality $[8,12,13]$. Thus, in order to select appropriate antibacterial agents for treating $P$. aeruginosa infection, it is necessary to regularly monitor and rapidly and accurately identify $P$. aeruginosa including MDRP strains in clinical specimens.

Currently, clinical assays for $P$. aeruginosa are typically conducted by bacterial culture. Generally, bacterial culture methods are the gold standard for detecting pathogens; however, culture methods have several limitations: (i) the detection of pathogens by culture methods is generally time-consuming (takes 2-3 days) [14, 15]; (ii) culture methods only detect culturable pathogens that have the ability to form colonies [16]; and (iii) culture methods can underestimate the number of pathogen due to selection bias induced by administered antibiotics that are present in human blood [17]. Accordingly, culture-based diagnostic procedures can produce false-negative results. Culture-negative sepsis is commonly observed in ICU patients: previous studies have shown negative blood cultures in $30 \%$ of septic shock patient [18]. It has also been reported that blood cultures from febrile neutropenic patients can identify the pathogens in only 17 to $42 \%$ of cases $[19,20]$. Thus, to overcome the problems associated with bacterial culture, we adopted Yakult Intestinal Flora-SCAN (YIF-SCAN®), a highly sensitive and rapid system based on quantitative reverse transcription PCR (qRT-PCR) [21-23]. YIF-SCAN® targets rRNA molecules that exist in bacteria abundantly (approximately $10^{4}$ copies per actively growing cell), the sensitivity of qRT-PCR is 100 times higher than that of qPCR assays that target rRNA genes (more than 10 copies/bacterial genome) [21]. Therefore, qRT-PCR is a more sensitive assay for detecting occult bacteria. Also, it requires only $6 \mathrm{~h}$ for the quantification of bacteria and detects only live bacteria from specimens [23]. Based on this, we applied this system to rapid and accurate diagnosis of $P$. aeruginosa infection.

In the present study, in order to establish a method that is useful in the early diagnosis of $P$. aeruginosa infection, to guide infection control measures, and to assess the results of antimicrobial treatment, we developed a novel $P$. aeruginosa quantification system based on 23S rRNA-targeted qRT-PCR. We demonstrated the detection sensitivity and specificity of the developed method and its applicability for monitoring enteric $P$. aeruginosa in ICU patients.

\section{Methods}

\section{Strains and culture conditions.}

The bacterial strains used are listed in Table 1. Each strain was routinely grown under the conditions listed in Additional File 1: Supplementary Table 1. The colony forming units (CFU) of $P$. aeruginosa were determined by culturing each strain aerobically on trypticase soy agar (TSA, Beckton Dickinson, Franklin Lakes, NJ, USA) or NCC agar at $37^{\circ} \mathrm{C}$ for $24 \mathrm{~h}$. NCC agar is a newly developed selective medium for the 
detection of $P$. aeruginosa in this study, and contains NAC (nalidixic acid, cetrimide) medium (Nissui Pharmaceutical, Tokyo, Japan) and TSA at a ratio of $1: 20$, and $0.5 \mu \mathrm{g} / \mathrm{ml}$ ceftizoxime sodium (ChemImpex International, Inc., Wood Dale, IL, USA) and $64 \mu \mathrm{g} / \mathrm{ml}$ cephalothin sodium crystalline (SigmaAldrich Co., St. Louis, MO, USA). Total bacterial cell counts of fresh cultures were determined using 4', 6diamidino-2-phenylindole (DAPI) staining according to a previously described method [24]. Based on total cell counts, each fresh culture was diluted to obtain $1 \mathrm{ml}$ of bacterial suspension containing $10^{9}$ cells. In the case of $P$. aeruginosa, the cells in the culture solution were dispersed using a $27 \mathrm{G}$ syringe with a needle (Terumo, Tokyo, Japan) prior to use in subsequent experiments. 
Table 1

Specificity tests with the newly designed primer set

\section{Taxon}

Pseudomonas aeruginosa

Pseudomonas aeruginosa

Pseudomonas aeruginosa

Pseudomonas aeruginosa

Pseudomonas aeruginosa

Pseudomonas aeruginosa

Pseudomonas alcaligenes

Pseudomonas fluorescens

Pseudomonas fluorescens

Pseudomonas brenneri

Pseudomonas luteola

Pseudomonas oryzihabitans

Pseudomonas oryzihabitans

Pseudomonas pseudoalcaligenes

Pseudomonas putida

Pseudomonas putida

Pseudomonas stutzeri

Pseudomonas tolaasii

Bacteroides vulgatus
Strain

ATCC $10145^{\top}$

ATCC 9027

ATCC 15442

JCM 2776

JCM 5961

DSM 6195

ATCC $14909^{\top}$

ATCC $13525^{\top}$

ATCC 15916

ATCC 49642

ATCC $43273^{\top}$

JCM $2952^{\top}$

JCM 3843

JCM 5968

ATCC $12633^{\top}$

ATCC 49128

ATCC $17588^{\top}$

ATCC $33618^{\top}$

ATCC $8482^{\top}$
Reaction $^{\mathrm{A}}$

[]

[

प

ㄱ

[]

[]

प

$\square$

प

प

प

$\square$

$\square$

प

प

प

प

प

[ 
Bifidobacterium adolescentis

Blautia producta

Clostridium difficile

Clostridium perfringens

Collinsella aerofaciens

Enterococcus faecalis

Escherichia coli

Faecalibacterium prausnitzii

Prevotella melaninogenica

Lactobacillus brevis

Lactobacillus casei

Lactobacillus fermentum

Lactobacillus fructivorans

Lactobacillus gasseri
ATCC $15703^{\top}$

JCM $1471^{\top}$

DSM $1296^{\top}$

JCM $1290^{\top}$

प

DSM $3979^{\top}$

प

ATCC $19433^{\top}$

प

ATCC $11775^{\top}$

प

ATCC $27768^{\top}$

प

ATCC $25845^{\top}$

[

ATCC $14869^{\top}$

प

ATCC $334^{\top}$

प

ATCC $14931^{\top}$

प

ATCC $8288^{\top}$

प

Page 6/30 
A The specificity of the qRT-PCR assay for target bacteria performed with the s-Pa-F/s-Pa-R primer set was investigated by using RNA extracts corresponding to $10^{5}$ cells from each strain described.

+: when it was more than that of $10^{4}$ standard cells; $\mathbb{t}$ : when it was less than that of $10^{1}$ standard cells.

\section{S rRNA gene sequencing of P. aeruginosa and related strains.}

We newly sequenced the $23 \mathrm{~S}$ rRNA genes of 6 strains of $P$. aeruginosa ( $P$. aeruginosa ATCC $10145^{\top}$ [accession number: LC515958], P. aeruginosa ATCC 9027 [accession number: LC515959], P. aeruginosa ATCC 15442 [accession number: LC515960], P. aeruginosa JCM 2776 [accession number: LC515961], $P$. aeruginosa JCM 5961 [accession number: LC515962], and P. aeruginosa DSM 6195 [accession number: LC515963]) and 8 species related to $P$. aeruginosa (P. alcaligenes ATCC $14909^{\top}$ [accession number: LC515970], $P$. fluorescens ATCC $13525^{\top}$ [accession number: LC515971], P. luteola ATCC $43273^{\top}$ [accession number: LC515966], P. oryzihabitans JCM 2952 ${ }^{\top}$ [accession number: LC515967], $P$. pseudoalcaligenes JCM 5968 ${ }^{\top}$ [accession number: LC515964], P. putida ATCC $12633^{\top}$ [accession number: LC515968], P. stutzeri ATCC $17588^{\top}$ [accession number: LC515965], and $P$. tolaasii ATCC $33618^{\top}$ [accession number: LC515969]) using the primer sets designed in this study for 23 S rRNA sequencing. qRT-PCR was conducted in a one-step reaction using a Qiagen OneStep RT-PCR kit (QIAGEN, Hilden, Germany), and the reaction mixture was incubated at $50{ }^{\circ} \mathrm{C}$ for $30 \mathrm{~min}$ for reverse transcription. The continuous amplification program consisted of one cycle at $95^{\circ} \mathrm{C}$ for $15 \mathrm{~min}$, followed by 45 cycles at 
$94{ }^{\circ} \mathrm{C}$ for $20 \mathrm{~s}$, followed by $20 \mathrm{~s}$ at the annealing temperature of each primer, and $72{ }^{\circ} \mathrm{C}$ for a duration according to the respective size of each amplicon. Each primer set used in the amplification is described in Additional File 2: Supplementary Table 2. Then, the amplified DNA fragment was sequenced, and the full-length 23S rRNA gene sequence was determined by a primer walking method. Sequencing was performed with a 3500 Genetic Analyzer (Applied Biosystems, Thermo Fisher Scientific Inc., Waltham, MA, USA) after the reaction using a BigDye Terminator v3.1 Cycle Sequencing Kit (Thermo Fisher Scientific Inc., Waltham, MA, USA) and purification.

\section{Development of 23S rRNA gene-targeted primers specific to $P$. aeruginosa.}

Multiple alignment of the 6 P. aeruginosa strains and 8 related species was performed with the CLUSTAL_X program [25] using the 23S rRNA gene sequences obtained from the previous experiment. After comparison of the sequences in silico, target sites for $P$. aeruginosa species-specific detection were identified, and a primer set, s-Pa-F (5囚-GTC TTT TAG ATG ACG AAG TGG-3囚) and s-Pa-R (5囚-TGG TAT CTT CGA CCA GCC AGA-3区), was newly constructed. The product size and annealing temperature were $234 \mathrm{bp}$ and $60^{\circ} \mathrm{C}$, respectively. The specificity of the designed primer pair was confirmed by submitting the sequences to the BLAST program of the National Center for Biotechnology Information (NCBI) (http://blast.ncbi.nlm.nih.gov/Blast.cgi).

\section{Total RNA extraction.}

For RNA stabilization, 2 volumes of RNAprotect Bacteria Reagent (QIAGEN, Hilden, Germany) were added to samples of each bacterial strain. After being kept for $10 \mathrm{~min}$ at room temperature, the bacterial suspensions were centrifuged at $13,000 \times g$ for $10 \mathrm{~min}$. The supernatant was discarded, and the pellet was stored at $-80^{\circ} \mathrm{C}$ until used for RNA extraction. RNA extraction was performed using a previously described method [21]. Briefly, each thawed sample was resuspended in a solution containing $346.5 \mu \mathrm{l}$ of RLT buffer (QIAGEN, Hilden, Germany), $3.5 \mu$ l of $\beta$-mercaptoethanol (Sigma-Aldrich Co., St. Louis, MO, USA), and $100 \mu$ of Tris-EDTA buffer (Wako Pure Chemical Industries, Osaka, Japan). Glass beads (300 mg; diameter, $0.1 \mathrm{~mm}$ ) (TOMY Seiko, Tokyo, Japan) were added to the suspension, and the mixture was vortexed vigorously for 5 min with a ShakeMaster Auto machine (BioMedical Science Inc., Tokyo, Japan). Then, $500 \mu \mathrm{l}$ of water-saturated phenol (Wako Pure Chemical Industries, Osaka, Japan) was added to the mixture, which was incubated at $60^{\circ} \mathrm{C}$ for $10 \mathrm{~min}$. Next, $100 \mu \mathrm{l}$ of chloroform-isoamyl alcohol (24:1) was added to the mixture. After centrifugation of the mixture at $13,000 \times g$ for 10 min at $4{ }^{\circ} \mathrm{C}$, the supernatant $(470 \mu \mathrm{l})$ was collected, and an equal volume of chloroform-isoamyl alcohol was added to it. After centrifugation at $12,000 \times g$ and $4{ }^{\circ} \mathrm{C}$ for $5 \mathrm{~min}$, the supernatant $(400 \mu \mathrm{l})$ was collected and subjected to isopropanol precipitation. Finally, the nucleic acid fraction was suspended in nucleasefree water (Ambion Inc., Waltham, MA, USA). 


\section{qRT-PCR.}

qRT-PCR was performed using a previously described method [21]. Briefly, in the case of bacterial cultures or blood samples, qRT-PCR was conducted in a one-step reaction using a Qiagen OneStep RT-PCR kit (QIAGEN, Hilden, Germany). The $20 \mu$ reaction mixture was composed of $1 \times$ Qiagen OneStep RT-PCR buffer, $0.5 \times \mathrm{Q}$-solution buffer, $400 \mu \mathrm{M}$ of each deoxynucleoside triphosphate, 1:100,000 dilution of SYBR green I (Lonza, Basel, Switzerland), $1 \mu$ l of Qiagen OneStep RT-PCR enzyme mixture, $0.6 \mu \mathrm{M}$ of each specific primer, and $2 \mu \mathrm{l}$ of template RNA. Amplification and detection were performed in 96-well optical plates (WATSON, Tokyo, Japan) using a 7500 Real-Time PCR System (Applied Biosystems, Thermo Fisher Scientific Inc., Waltham, MA, USA). In the case of fecal samples, qRT-PCR was performed with a Qiagen OneStep RT-PCR kit. The $10 \mu \mathrm{l}$ reaction mixture was composed of $1 \times$ Qiagen OneStep RT-PCR buffer, $0.5 \times$ Q-solution buffer, $400 \mu \mathrm{M}$ of each deoxynucleoside triphosphate, 1:100,000 dilution of SYBR green I, $0.4 \mu \mathrm{l}$ of Qiagen OneStep RT-PCR enzyme mixture, $0.6 \mu \mathrm{M}$ of each specific primer, and $5 \mu \mathrm{l}$ of template RNA. Amplification and detection were performed in 384-well optical plates (Life Technologies, Carlsbad, CA, USA) with a QuantStudio ${ }^{\text {TM }}$ 12K Flex Real-Time PCR System (Applied Biosystems, Thermo Fisher Scientific Inc., Waltham, MA, USA). The reaction mixture was incubated at $50^{\circ} \mathrm{C}$ for $30 \mathrm{~min}$ for reverse transcription. In either case, the continuous amplification program consisted of one cycle at $95^{\circ} \mathrm{C}$ for $15 \mathrm{~min}$ and $45 \mathrm{cycles}$ at $94^{\circ} \mathrm{C}$ for $20 \mathrm{~s}, 60^{\circ} \mathrm{C}$ for $20 \mathrm{~s}$, and $72{ }^{\circ} \mathrm{C}$ for $35 \mathrm{~s}$. A melting curve was obtained to distinguish targeted PCR products from non-targeted ones by slow heating at temperatures from 60 to $95^{\circ} \mathrm{C}$ at a rate of $0.2^{\circ} \mathrm{C} / \mathrm{s}$ with continuous fluorescence collection. Standard curves for $P$. aeruginosa ATCC $10145^{\top}$ were generated by using the threshold cycle $\left(C_{T}\right)$ values and the corresponding cell counts, which were determined microscopically with DAPI staining as described elsewhere. $C_{T}$ values in the linear range of the assay were applied to the analytical curve generated in the same experiment to obtain the corresponding bacterial count in each nucleic acid sample; this count was converted to the count per sample.

\section{DNA extraction and qPCR.}

Fresh cultures of each bacterial strain $(1 \mathrm{ml})$ were centrifuged at $13,000 \times g$ for $10 \mathrm{~min}$. Then, the supernatant $(800 \mu \mathrm{l})$ was discarded and the pellet was stored at $-80^{\circ} \mathrm{C}$ until used for DNA extraction. The bacterial suspension $(200 \mu \mathrm{l})$ was subjected to DNA extraction. RNA extraction and qPCR were performed using a previously described method [26]. Briefly, each thawed sample was mixed with $250 \mu$ of extraction buffer (100 mM Tris-HCl, $40 \mathrm{mM}$ EDTA; $\mathrm{pH}$ 9.0) and $50 \mu \mathrm{l}$ of $10 \%$ sodium dodecyl sulfate. Glass beads ( $300 \mathrm{mg}$; diameter, $0.1 \mathrm{~mm}$ ) and $500 \mu \mathrm{l}$ of Tris-EDTA (TE)-saturated phenol were added to the suspension, and the mixture was subjected to vigorous vortexing for $10 \mathrm{~min}$ on a ShakeMaster Auto apparatus (Bio Medical Science Inc., Tokyo, Japan). After phenol-chloroform purification and isopropanol precipitation, the nucleic acid fraction was suspended in $100 \mu$ of nuclease-free water. qPCR was carried out using a Qiagen OneStep RT-PCR kit (QIAGEN, Hilden, Germany). Each reaction mixture $(20 \mu \mathrm{l})$ contained the same components as those for qRT-PCR, except for the replacement of $2 \mu$ template RNA 
with the same amount of template DNA. The reaction mixture was incubated at $95^{\circ} \mathrm{C}$ for $15 \mathrm{~min}$ and 45 cycles at $94{ }^{\circ} \mathrm{C}$ for $20 \mathrm{~s}, 60^{\circ} \mathrm{C}$ for $20 \mathrm{~s}$, and $72{ }^{\circ} \mathrm{C}$ for $35 \mathrm{~s}$. The subsequent procedures were the same as those for qRT-PCR.

\section{Determination of primer specificity.}

Total RNA fractions extracted from the bacterial cells of each strain (shown in Table 1) at a dosorresponding to $10^{5}$ cells were assessed by qRT-PCR using the primer set of s-Pa-F and s-Pa-R. Using the standard curve for $P$. aeruginosa as described above, we judged the amplified signal to be positive (+) when it was more than that of $10^{4}$ standard cells and negative (-) when it was less than that of $10^{1}$ standard cells. The amplified signal was also defined as negative $(-)$ when the corresponding melting curve had a peak different from that of the standard strain.

\section{Determination of qRT-PCR sensitivity.}

Total RNA and DNA fractions of the 6 strains of $P$. aeruginosa were extracted from culture samples, and bacterial counts were determined microscopically with DAPI staining as described elsewhere. Serial RNA and DNA dilutions corresponding to bacterial counts ranging from $10^{-2}$ to $10^{4}$ cells were assessed by qRT-PCR and qPCR assays, respectively. The range of RNA and DNA concentrations at which there was linearity with the $C_{T}$ value was confirmed. Results are expressed as the mean and standard deviation of the results from triplicate samples.

\section{Quantification of P. aeruginosa spiked to human blood by qRT-PCR and culture methods.}

Commercially available human blood type A (Kohjin Bio Co., Saitama, Japan) was used in this study to determine the detection limit of qRT-PCR and to compare the bacterial counts determined by qRT-PCR and the culture method. P. aeruginosa ATCC $10145^{\top}$ prepared as described above was serially diluted with $1 \%$ Tween 20 (Wako Pure Chemical Industries, Osaka, Japan) in trypticase soy broth (TSB, Beckton Dickinson Co., Franklin Lakes, NJ, USA) and then spiked to make final concentrations ranging from $10^{0}$ to $10^{4}$ cells $/ \mathrm{ml}$ of blood. For qRT-PCR assays, $1 \mathrm{ml}$ of the blood sample was added to $2 \mathrm{ml}$ of RNAprotect bacterial reagent (QIAGEN, Hilden, Germany). After being kept for $10 \mathrm{~min}$ at room temperature and centrifuged at $15,000 \times g$ for $10 \mathrm{~min}$, the pellet was stored at $-80^{\circ} \mathrm{C}$ until used for RNA extraction. Then, RNA fractions extracted from the mixture were assessed by qRT-PCR assay. The obtained $C_{T}$ values were applied to the standard curve generated with the RNA dilution series for $P$. aeruginosa ATCC $10145^{\top}$ to determine the qRT-PCR counts with the primer set of s-Pa-F and s-Pa-R. For the culture method, to avoid the effect of reduced colony-forming capacity by the presence of antimicrobial substances in human blood such as lysozyme and complement proteins, the $P$. aeruginosa-spiked human blood sample was 
immediately cultured on NCC agar plates. One $\mathrm{ml}$ of each appropriate dilution series of blood sample was cultured on 10 culture plates $\left(100 \mu \mathrm{l}\right.$ each), at $37^{\circ} \mathrm{C}$ for $24 \mathrm{~h}$. The CFU counts of $P$. aeruginosa in $1 \mathrm{ml}$ of blood was calculated by summed up the results of 10 culture plates.

\section{Quantification of P. aeruginosa added to human feces by qRT-PCR and culture methods.}

Fecal samples collected from three healthy adult volunteers who had been confirmed in advance by qRTPCR not to include $P$. aeruginosa in their indigenous intestinal populations were used in this study. Each fecal sample was weighed and suspended in 9 volumes of TSB. P. aeruginosa ATCC $10145^{\top}$ prepared as described above was serially diluted with $1 \%$ Tween 20 in TSB and then spiked at final concentrations ranging from $10^{2}$ to $10^{7}$ cells/g of feces. In preparation for total RNA extraction, $400 \mu$ of each fecal homogenate was added to $800 \mu$ of RNA later (Ambion Inc., Waltham, MA, USA). After being kept for $10 \mathrm{~min}$ at room temperature, $120 \mu \mathrm{l}$ of the mixture was added to $1 \mathrm{ml}$ of Dulbecco's PBS (-) (Nissui Pharmaceutical Co., Tokyo, Japan) Then, after centrifugation of the mixture at $15,000 \times g$ for $10 \mathrm{~min}$, the pellet was stored at $-80{ }^{\circ} \mathrm{C}$ until used for RNA extraction. RNA fractions extracted from the pellet were assessed by qRT-PCR assays. The $C_{T}$ values obtained were applied to the standard curve generated with the RNA dilution series for $P$. aeruginosa ATCC $10145^{\top}$ to determine the qRT-PCR counts with the primer set of s-Pa-F and s-Pa-R. For the culture method, $100 \mu \mathrm{l}$ of each appropriate dilution series of fecal homogenate was cultured on NCC agar plates at $37^{\circ} \mathrm{C}$ for $24 \mathrm{~h}$.

\section{Monitoring of MDRP exposed to antibiotics by three different methods.}

$P$. aeruginosa ATCC BAA-2108 ${ }^{\mathrm{TM}}$ adjusted to a final concentration of $10^{6} \mathrm{CFU} / \mathrm{ml}$ was cultured in Dulbecco's modified Eagle's medium (DMEM, Gibco, Waltham, MA, USA) containing $10 \%$ fetal bovine serum (FBS, Gibco, Waltham, MA, USA), 1\% MEM nonessential amino acids (Gibco, Waltham, MA, USA), $5 \mu \mathrm{g} / \mathrm{ml}$ colistin sulfate salt (Sigma-Aldrich Co., St. Louis, MO, USA), and $100 \mu \mathrm{g} / \mathrm{ml}$ doripenem hydrate (SHIONOGI \& CO., LTD., Osaka, Japan) at $37{ }^{\circ} \mathrm{C}$ with shaking (140 rpm). After the start of culture, $10 \mathrm{ml}$ of the culture solution was periodically sampled and washed by centrifugation at $13,000 \times g$ for 10 min, and the supernatant was discarded. The precipitated pellets were resuspended in $10 \mathrm{ml}$ of antibiotic-free and serum-free DMEM. Then, the culture solution was distributed for RNA extraction (1 ml), DNA extraction $(1 \mathrm{ml})$, culturing for CFU counts $(1 \mathrm{ml})$, cell infection $(2 \mathrm{ml})$, and acquisition of fluorescent images $(3 \mathrm{ml})$. For RNA extraction, $1 \mathrm{ml}$ of the dispersed culture solution was added to $2 \mathrm{ml}$ of RNA later. After being kept for $10 \mathrm{~min}$ at room temperature and centrifuged at $15,000 \times \mathrm{g}$ for $10 \mathrm{~min}$, the pellet was stored at $-80^{\circ} \mathrm{C}$ until used for RNA extraction. RNA extraction and qRT-PCR with the primer set s-Pa-F/s-Pa-R were performed as described above. Also, for DNA extraction, $1 \mathrm{ml}$ of the dispersed culture solution was centrifuged at $15,000 \times g$ for $10 \mathrm{~min}$, and the pellet was stored at $-80^{\circ} \mathrm{C}$ until used for DNA extraction. 


\section{Infection of Caco-2 cells with MDRP exposed to antibiotics.}

Caco-2 cells (86010202) obtained from Public Health England (London, UK) were grown in DMEM supplemented with 10\% FBS, 1\% MEM nonessential amino acids, 1\% penicillin-streptomycin (10,000 units $/ \mathrm{ml}$ penicillin, $10,000 \mu \mathrm{g} / \mathrm{ml}$ streptomycin) (Gibco, Waltham, MA, USA) at $37^{\circ} \mathrm{C}$ in the presence of humidified $5 \% \mathrm{CO}_{2}$ in air. Cells were plated on 6-well plates (Costar, Corning, NY, USA) at a density of $3.0 \times$ $10^{5}$ cells/well and incubated for $24 \mathrm{~h}$ for the infection assays. After incubation, the cells were washed three times with D-PBS (Thermo Fisher Scientific Inc., Waltham, MA, USA) to remove penicillin G and streptomycin contained in the cell culture. For cell infection, $2 \mathrm{ml}$ of MDRP suspension treated with antibiotics and washed as described above was applied to the cells, and cells were incubated at $37^{\circ} \mathrm{C}$ with $5 \% \mathrm{CO}_{2}$ in air for $6 \mathrm{~h}$. To compare with a reference value of uninfected cells, fresh antibiotic-free culture medium was also applied to the cells as a control, and then the cells were incubated at $37^{\circ} \mathrm{C}$ with $5 \% \mathrm{CO}_{2}$ in air for $6 \mathrm{~h}$.

\section{Quantification of inflammatory response in infected Caco-2 cells.}

The bacterial proinflammatory effect was assessed by measuring the transcription level of IL-8 and IL-8 secretion in infected Caco-2 cells. After a 6-hour incubation, $2 \mathrm{ml}$ of the cell culture medium was sampled to measure IL-8 production. The medium was centrifuged at 2,300 $\mathrm{g}$ for $5 \mathrm{~min}$, and the supernatant was stored at $-80{ }^{\circ} \mathrm{C}$ until used for determinations. Then, total RNA was extracted from infected Caco- 2 cells using TRIzol reagent (Thermo Fisher Scientific Inc., Waltham, MA, USA). qRT-PCR was performed in 96well optical plates with a 7500 Real-Time PCR System (Applied Biosystems, Thermo Fisher Scientific Inc., Waltham, MA, USA) using a Qiagen OneStep RT-PCR kit (QIAGEN, Hilden, Germany), and the reaction mixture was incubated at $95^{\circ} \mathrm{C}$ for $15 \mathrm{~min}$ and 45 cycles at $94{ }^{\circ} \mathrm{C}$ for $20 \mathrm{~s}, 60{ }^{\circ} \mathrm{C}$ for $20 \mathrm{~s}$, and $72{ }^{\circ} \mathrm{C}$ for $35 \mathrm{~s}$. The following primers were used: IL-8, 5’-AGGACAAGAGCCAGGAAGAA-3’ (forward primer) and 5’CAGAGCTGCAGAAATCAGGA-3' (reverse primer) [27]; GAPDH, 5'-GGAGCGAGATCCCTCCAAAAT-3' (forward primer) and 5'-GGCTGTTGTCATACTTCTCATGG-3' (reverse primer) [28]. Standard curves were obtained for each primer set with serial dilutions of RNA. The RNA used for standard RNA solutions was extracted from Caco-2 cells infected with $P$. aeruginosa following culturing for $6 \mathrm{~h}$ on medium containing antibiotics. The relative amounts of IL-8-encoding transcripts were calculated and normalized to that of GAPDH, and the relative gene expression values were compared to those of uninfected cells (treated with DMEM not containing antimicrobials; $n=4)$. IL-8 levels in cell culture supernatants were assayed using an ELISA Quantikine kit (BioLegend, San Diego, CA, USA) according to the manufacturer's protocol. 


\section{Observation and acquisition of fluorescent images of MDRP.}

Fluorescence in situ hybridization (FISH) analyses were performed as described previously with minor modifications [29]. Briefly, the bacterial suspension for acquisition of fluorescent images, which was sampled at 0,48 , and $336 \mathrm{~h}$ after cultivation, was centrifuged at $13,000 \times \mathrm{g}$ for $10 \mathrm{~min}$ and condensed to 100 times concentration. The suspension was fixed with 3 volumes of $4 \%$ paraformaldehyde and left at $4{ }^{\circ} \mathrm{C}$ for $16 \mathrm{~h}$. Ten microliters of the fixed sample, after being condensed to 4 times the concentration by centrifugation, was smeared on a MAS-coated slide glass (Matsunami Glass Ind., Ltd., Osaka, Japan), which was then hybridized with the TAMRA-labeled 16S rRNA probe Eub338 (5'-

GCTGCCTCCCGTAGGAGT-3'). After washing once more with distilled water, the cover glass was mounted with mounting medium containing DAPI (VECTASHIELD with DAPI, Vector Laboratories, Burlingame, CA, USA). An automated Leica DM6000 B research microscope was used for fluorescence observation and image acquisition. All fluorescent images obtained were analyzed (HiGauss and flattening) using image analysis software (Image-Pro Plus v. 5.1, Media Cybernetics, Inc., Rockville, MD).

\section{qRT-PCR quantification of P. aeruginosa and monitoring of drug-resistant $P$. aeruginosa in clinical samples.}

For the analysis of clinical samples, we used total RNA isolated from fecal samples collected in a previous study [30], which were stored at $-80^{\circ} \mathrm{C}$ until used in this study. In the previous study, fecal samples were acquired from 65 patients who were more than 16 years old and had been placed on a ventilator within 3 days after admission to the ICU, and who were diagnosed as having sepsis in the Department of Traumatology and Acute Critical Medicine, Osaka University Medical School, and Osaka General Medical Center during the period from November 2011 to September 2016. If sepsis occurred, patients were initially treated empirically for the underlying clinical syndrome and then according to the results of antibiotic susceptibility testing of the bacterial isolate causing the sepsis. Antibiotics were administered under the same policy during the entire study period. Also, we collected fecal samples from 44 healthy Japanese adults and prepared total RNA in the same manner as for the clinical samples, as described above. Then, three serial dilutions of each extracted RNA sample were used for qRT-PCR, and the $C_{T}$ values obtained were applied to the standard curve generated with the RNA dilution series for $P$. aeruginosa ATCC $10145^{\top}$ to determine the qRT-PCR counts with the primer set of s-Pa-F and s-Pa-R. For monitoring of drug-resistant $P$. aeruginosa in fecal samples from 4 ICU patients, qRT-PCR was used to check for the presence of resistance genes using the following specific primers: b/a $a_{\mathrm{MP}}, 5^{\prime}-$

GGAATAGAGTGGCTTAAYTCTC-3' (forward primer) and 5'-GGTTTAAYAAAACAACCACC-3' (reverse primer) [31]; ampC, 5'-GGGCTGGCCTCGAAAGAGGAC-3' (forward primer) and 5'- GCACCGAGTCGGGGAACTGCA-3' (reverse primer) [32]; and mexA, 5'-AACCCGAACAACGAGCTG-3' (forward primer) and 5'-

ATGGCCTTCTGCTTGACG-3' (reverse primer) [33], in combination with the primer set of s-Pa-F and s-Pa-R. Each different reaction mixture was incubated at $95^{\circ} \mathrm{C}$ for $15 \mathrm{~min}$ and 45 cycles at $94^{\circ} \mathrm{C}$ for $20 \mathrm{~s}, 60^{\circ} \mathrm{C}$ 
for $20 \mathrm{~s}$, and $72{ }^{\circ} \mathrm{C}$ for $35 \mathrm{~s}$. To confirm the validity of the qRT-PCR amplification, sequence analysis of the RT-PCR products was performed [34].

\section{Fecal microbiota analysis.}

The microbiota compositions of 4 ICU patients were analyzed using the YIF-SCAN® version of a 16 S and 23S rRNA-targeted qRT-PCR system using specific primers for the 6 most prevalent obligate anaerobic bacterial groups (Clostridium coccoides group, C. leptum subgroup, Bacteroides fragilis group, Bifidobacterium, Atopobium cluster, and Prevotella) and 5 facultative anaerobic and aerobic bacterial groups (Lactobacillus, Enterobacteriaceae, Enterococcus, and Staphylococcus] as described previously $[21,22]$. A standard curve was generated with qRT-PCR using the $C_{T}$ value, i.e., the cycle number when the threshold fluorescence was reached, and the corresponding cell count was determined microscopically with DAPI staining for a dilution series of the standard strains as described elsewhere. To determine the types of bacteria present in the samples, three serial dilutions of an extracted RNA sample were used for qRT-PCR, and the $C_{T}$ values in the linear range of the assay were applied to the standard curve to obtain the corresponding bacterial cell counts in each nucleic acid sample. These data were then used to determine the number of bacteria per sample.

\section{Statistical analysis.}

Statistical analyses were performed using IBM SPSS Statistics Desktop version 22.0 software (IBM Japan Ltd., Tokyo, Japan). Fisher's exact test was used to compare the detection rate of $P$. aeruginosa between 2 groups. The Mann-Whitney $U$ test (2-tailed) was used to compare the average $P$. aeruginosa counts between 2 groups. Pearson's correlation coefficient was used to analyze the relationship between the $P$. aeruginosa count quantified with each measurement method and the cytokine levels of the infected Caco-2 cells. $P$ values $<0.05$ were considered statistically significant. Spearman's rank correlation coefficient was used to analyze the association between the number of $P$. aeruginosa and fecal occupation rate of representative microorganisms.

\section{Results}

\section{The newly designed primer set for the detection of $P$. aeruginosa shows excellent specificity.}

The specificity of the newly designed primer set, s-Pa-F/s-Pa-R, was evaluated by qRT-PCR with total RNA (corresponding to $10^{5}$ cells) template extracted from each pure culture of 39 strains, including 6 strains of $P$. aeruginosa, 12 species related to $P$. aeruginosa, and 21 strains of enteric bacteria or causative agents of human intestinal tract infectious disease (Table 1). The s-Pa-F/s-Pa-R primer set reacted strongly with 
the 6 strains of $P$. aeruginosa, but showed no reaction with the other 33 bacterial strains investigated. Therefore, the newly designed primer set targeting $P$. aeruginosa was specific for the target strains.

\section{Specific quantification of cultured P. aeruginosa by qRT-PCR has a lower detection limit compared to qPCR.}

The counts of $P$. aeruginosa in pure cultures obtained by DAPI staining and $C_{T}$ values obtained by qRTPCR showed good correlation for the 6 strains of $P$. aeruginosa $\left(R^{2}=0.9977-0.9999\right)$ (Fig. 1). The counts of $P$. aeruginosa also correlated well with the $C_{T}$ values obtained by qPCR $\left(\mathrm{R}^{2}=0.9979-0.9998\right)$; however, the detection limit was $10^{0}$ cells/reaction for the $6 P$. aeruginosa strains (Fig. 1). These results indicated that qRT-PCR is approximately 100 -fold more sensitive than QPCR for the quantification of $P$. aeruginosa. The parameters from the linear regression analyses for the 6 different $P$. aeruginosa strains were highly similar, indicating they had the same quantitative performance (Fig. 1G).

\section{qRT-PCR can quantitate the number of P. aeruginosa spiked in human blood or feces with good correlation with the culture method.}

The spiked bacterial counts could be detected by qRT-PCR using the primer set s-Pa-F/s-Pa-R, at the lowest concentration of $10^{0.3}$ cells $/ \mathrm{ml}$ of blood and $10^{2.4} \mathrm{cell} / \mathrm{s} / \mathrm{g}$ of feces. In addition, the bacterial counts detected by the culture method and those determined by qRT-PCR showed good correlation (Fig. 2A, 2B). These results indicated that our qRT-PCR method enabled quantitative detection of $P$. aeruginosa in blood with the lowest detection limit of $10^{0} \mathrm{cells} / \mathrm{ml}$ of blood and in feces with the lowest detection limit of $10^{2}$ cells/g of feces.

\section{In vitro experiments revealed that the number of MDRP obtained by qRT-PCR accurately correlated with inflammatory cytokine production in Caco-2 cells.}

Changes over time in the counts of MDRP treated with antibiotics were measured with qRT-PCR using the $P$. aeruginosa-specific primers, bacterial culture, and qPCR. The detected counts differed greatly depending on the measurement method (Fig. 3A). The counts detected with qRT-PCR gradually decreased until $336 \mathrm{~h}$ after antibiotic treatment. In contrast, the counts detected with qPCR showed almost no change from soon after antibiotic treatment ( $6 \mathrm{~h}$ after antibiotic treatment) to $336 \mathrm{~h}$ after antibiotic treatment. The counts detected with the culture method decreased rapidly after antibiotic treatment. Bacteria were no longer detected $48 \mathrm{~h}$ after treatment (detection limit: $<1 \mathrm{cell} / \mathrm{ml}$ ). 
When the above-mentioned $P$. aeruginosa solution was observed with FISH, a large number of viable bacteria were observed at the start of antibiotic treatment; however, the number of bacteria dramatically decreased after $48 \mathrm{~h}$, and almost no viable bacteria could be observed after $336 \mathrm{~h}$ (Fig. 3B).

Next, $P$. aeruginosa solutions treated with antibiotics were sampled over time and used to infect Caco-2 cells. The relationship between the inflammatory response and the $P$. aeruginosa counts obtained with each measurement method was then evaluated (Fig. 3C). Results showed that while the IL-8 gene expression level and production level in Caco-2 cells increased more than 10-fold and 9-fold, respectively, when infected with $P$. aeruginosa at $6 \mathrm{~h}$ after antibiotic treatment, these decreased as the duration of antibiotic treatment increased. At $336 \mathrm{~h}$ after treatment, they had decreased to less than half and onetenth, respectively, compared to the levels at $6 \mathrm{~h}$ after antibiotic treatment. Even at $48 \mathrm{~h}$ after antibiotic treatment, when $P$. aeruginosa was no longer detectable by the culture method, the IL-8 gene expression and secretion levels were very high (gene expression level: 4-6 times higher than when not infected; production: 7-10 times higher than when not infected). At the point when no decrease in cell counts from antibiotic treatment was seen with qPCR at $336 \mathrm{~h}$, IL-8 gene expression and production had decreased remarkably. Trend in the $P$. aeruginosa cell count monitored by qRT-PCR is similar with the level of the Caco-2 cell II-8 production; however, the results of the culture method and qPCR for the cell count did not similarly reflect the level of the Caco-2 cell IL-8 production (Fig. 3C).

In a correlation diagram, a significant correlation was seen between the cell count obtained with qRT-PCR and the Caco-2 cell IL-8 gene expression and protein levels (IL-8 gene expression level: $R=0.778, P=0$. 00003 , IL-8 production: $\mathrm{R}=0.600, \mathrm{P}=0.004$ ) (Fig. 3D). Similar correlations were not seen with the culture method (IL-8 gene expression level: $R=0.143, P=0.803$, IL-8 production: $R=0.314, P=0.564$ ) or $q P C R$ (IL8 gene expression level: $R=0.653, P=0.00054$, IL-8 production: $R=0.366, P=0.079)$ (Fig. 3D).

\section{qRT-PCR can detect P. aeruginosa from human fecal samples.}

To examine whether the qRT-PCR system using the newly designed primer set can be applied to clinical samples, qRT-PCR analysis was performed using fecal samples collected from 65 patients who were placed on a ventilator within 3 days after admission to the ICU (44 males and 21 females aged 20 to 97 years [average \pm SD, $61 \pm 19$ years]). P. aeruginosa was detected in 32 clinical samples $(49.2 \%)$ at an average count of $10^{5.48 \pm 1.90}$ cells/g of feces (Table 2). For comparison, the presence of $P$. aeruginosa in fecal specimens collected from healthy adults (26 males and 18 females aged 23 to 59 years [average \pm SD, $39 \pm 10$ years]) was also tested. As a result, 6 out of 44 healthy volunteer samples $(13.6 \%)$ were positive for $P$. aeruginosa, and the average count was $10^{4.38 \pm 1.21} \mathrm{cell} \mathrm{s} / \mathrm{g}$ of feces (Table 2 ). The detection ratio in ICU patients was significantly higher than that in healthy volunteers $(P<0.05)$. As for bacterial counts, while some patients in ICU showed high levels of $P$. aeruginosa in the feces $\left(10^{8}\right.$ cells $/ \mathrm{g}$ of feces), some patients had it at very low levels $\left(10^{2} \mathrm{cells} / \mathrm{g}\right.$ of feces) as observed in healthy volunteers. 
Table 2

qRT-PCR quantification of $P$. aeruginosa in fecal samples of ICU patients and healthy volunteers

\begin{tabular}{|c|c|c|c|c|}
\hline Groups & $\begin{array}{l}\mathrm{n} \text { (by } \\
\text { gender) }\end{array}$ & $\begin{array}{l}\text { Age range (year, } \\
\text { mean } \pm S D)\end{array}$ & $\begin{array}{l}\text { Bacterial counts } \\
\text { (Detection range) }^{B}\end{array}$ & $\begin{array}{l}\text { Detection } \\
\text { ratio }\end{array}$ \\
\hline $\begin{array}{l}\text { ICU patients }(n= \\
65)\end{array}$ & $\begin{array}{l}65(\mathrm{M} 44 \\
\mathrm{F} 21)\end{array}$ & $20-97(61 \pm 19)$ & $5.48 \pm 1.90(2.32-8.88)$ & $\begin{array}{l}49.2 \%(32 / \\
65)^{*}\end{array}$ \\
\hline $\begin{array}{l}\text { Healthy adults } \\
(\mathrm{n}=44)\end{array}$ & $\begin{array}{l}44(M 26 \\
F 18)\end{array}$ & $23-59(39 \pm 11)$ & $4.38 \pm 1.21(3.12-5.98)$ & $\begin{array}{l}13.6 \%(6 / \\
44)\end{array}$ \\
\hline \multicolumn{5}{|c|}{${ }^{A} M$, male; $F$, female } \\
\hline \multicolumn{5}{|c|}{${ }^{B} \log _{10}$ cells $/ g$ of feces, data are expressed as the mean \pm SD. } \\
\hline \multicolumn{5}{|c|}{${ }^{\star} \mathrm{P}<0.05$ : ICU patients vs healthy adults (Fisher's exact test) } \\
\hline \multicolumn{5}{|c|}{ Detection limit: $<2.3\left(\log _{10}\right.$ cells/g of feces) } \\
\hline
\end{tabular}

\section{The combined use of primers targeting P. aeruginosa- specific 23S rRNA and drug resistance genes can monitor the presence of drug-resistant P. aeruginosa in human fecal samples.}

When $P$. aeruginosa counts in the feces of ICU patients undergoing antibiotic treatment (4 patients) were measured with qRT-PCR using the new $P$. aeruginosa-specific primers, we were able to monitor abnormal proliferation and excessive decreases of $P$. aeruginosa in the intestines within a range of $<10^{2} \mathrm{cells} / \mathrm{g}$ to $10^{9}$ cells/g (Fig. 4). Monitoring of drug-resistant $P$. aeruginosa was also possible with the combined use of drug-resistance gene amplification primers and the $P$. aeruginosa-specific primers (Fig. 4 ). In the four patients in whom $P$. aeruginosa was detected from the feces, a drug efflux pump gene (mexA) and the AmpC $\beta$-lactamase gene $(a m p C)$ were detected from the feces of all patients (Fig. 4, A-D). From Patient B, who was receiving meropenem (a carbapenem antibiotic), a metallo- $\beta$-lactamase encoding gene (b/a $a_{\mathrm{IMP}}$ ) was detected (Fig. 4B).

Trend in $P$. aeruginosa counts in the feces of ICU patients monitored by the qRT-PCR method were related to whether or not antibiotics were being administered, whether or not an artificial ventilator was being used, and the composition of the patients' intestinal microbiota (Fig. 4, Additional file 3: Supplementary Table 3). In Patient A, explosive proliferation of $P$. aeruginosa in the intestines was induced at the time (Day 30) when obligate anaerobe groups in the intestines rapidly decreased with the administration of antibiotics (Fig. 4A). Similar trends were seen in Patient B (Day 15, Day 41) and Patient D (Day 16) (Fig. 4B, D). In contrast, when the administration of antibiotics was ceased, the $P$. aeruginosa count in patients' intestines decreased (Patient A: Day 38, Patient C: Day 31, Patient D: Day 23) (Fig. 4A, C, D). In 
two patients taken off from artificial ventilators, intestinal counts of drug-resistant $P$. aeruginosa decreased to below the detection limit at the time when the counts of the most prevalent obligate anaerobes in the intestines recovered after ventilator withdrawal (Patient C: Day 31, D: Day 23) (Fig. 4C, D).

Negative correlations were seen between the $P$. aeruginosa counts in the intestines of ICU patients and the proportion of total obligate anaerobes. In contrast, positive correlations were seen between $P$. aeruginosa counts in the feces of ICU patients and the proportions of total facultative anaerobes and aerobes. Specifically, the proportions of Clostridium coccoides group, C. leptum subgroup, and Atopobium cluster were negatively correlated, whereas the proportion of Enterobacteriaceae was positively correlated with the $P$. aeruginosa counts (Fig. 4E).

\section{Discussion}

For $P$. aeruginosa infection, nosocomial infection control and appropriate antimicrobial treatment have become important issues. Diagnosis plays an important role in managing $P$. aeruginosa infection, but conventional inspection methods such as bacterial culture and QPCR are limited by low sensitivity and inaccuracy $[35,36]$. However, using qRT-PCR with the newly developed $23 S$ rRNA-targeted primers specific to $P$. aeruginosa, $P$. aeruginosa was detected from $1 \mathrm{cell} / \mathrm{ml}$ of blood and $10^{2}$ cells $/ \mathrm{g}$ of feces in in vitro experiments using spiked samples (equivalent to a sensitivity more than 100 times greater than qPCR; Fig. 1), with high specificity and quantifiability. When this qRT-PCR method was applied to fecal samples from ICU patients, it was demonstrated that $P$. aeruginosa had colonized some patients at very low levels $\left(10^{2}\right.$ cells/g of feces) in the intestine, as observed in healthy subjects. qRT-PCR was shown to be useful in the screening of patients who carry minute amounts of $P$. aeruginosa, which are easy to miss with conventional methods. Measurements of $P$. aeruginosa in clinical samples other than feces and environmental samples have also been reported to be important in the control of $P$. aeruginosa infection in ICU patients $[37,38]$. The current qRT-PCR method was able to accurately quantify $P$. aeruginosa even in fecal samples that contain large numbers of bacteria and PCR inhibitors. This suggests that the qRTPCR method can be applied to a wide range of samples, including bronchoalveolar lavage fluid, sputum, intraperitoneal drainage fluid, devices, and environmental samples such as hospital sewage.

The proper timing of antibiotic administration is very important in the treatment of $P$. aeruginosa infection. The results of microorganism tests such as culturing and QPCR and patients' clinical conditions do not necessarily coincide [18-20]. In our experimental system using $P$. aeruginosa-infected cells, the counts of $P$. aeruginosa by qRT-PCR correlated well with the inflammatory response (IL-8 gene expression and production level) of infected cells compared to culturing and qPCR. IL-8 is a biomarker that reflects the severity of infection, including the inflammatory response and risk of death $[39,40]$. Also, IL-8 production is almost entirely dependent on the type III secretion of exotoxin $[41,42]$ which is a major determinant of virulence and is associated with disease severity in the infected host $[43,44]$. Given this, the detection of viable $P$. aeruginosa with infectivity would seem to be essential in understanding the infectiveness, inflammation induction, and pathogenesis in the host. The qRT-PCR method can measure 
only live bacteria, as it targets rRNA that is rapidly degraded in dead cells [21]. Given this, we think that the bacterial count as measured by the qRT-PCR method closely reflected the extent of the inflammatory response of infected cells. In contrast, with qPCR, which targets DNA, the correlation between the detected $P$. aeruginosa number and the inflammatory response of infected cells was weak. Moreover, we observed that DAPI staining, which targets DNA, and fluorescence microscopy images remained fairly constant even at the death phase, so dead $P$. aeruginosa continued to be observed after antibiotic treatment (Fig. 3B). Therefore, with qPCR, the poor correlation between the detected $P$. aeruginosa number and the inflammatory response may be attributed to the detection of both viable and dead cells. The discrepancy between bacterial count results with culture methods and the inflammatory response of infected cells is thought to be due mainly to a decrease in the ability of $P$. aeruginosa to form colonies in a viable but nonculturable state $[45,46]$ under antibiotic treatment.

Previous reports indicated that more than $70 \%$ of ICU patients receive antimicrobial treatment and are therefore susceptible to development of drug-resistant $P$. aeruginosa infection $[47,48]$. In this study, we demonstrated that intestinal infections of drug-resistant $P$. aeruginosa in ICU patients can be quickly detected using qRT-PCR with the combined use of drug-resistance gene amplification primers. It has been reported that among antipseudomonas antibiotics, meropenem is associated with the highest risk of resistance emergence $[49,50]$. In Patient $B$ in this study, who had received meropenem for more than 2 weeks, an elevated fecal $P$. aeruginosa count was observed and upregulation of drug resistance genes such as the $b / a_{\mathrm{IMP}}$, $a m p C$, and mex $A$ gene was detected. About $80 \%$ of carbapenem-resistant $P$. aeruginosa have been reported to be multidrug resistant [51]. Furthermore, $P$. aeruginosa actually proliferates in the intestines during the administration of levofloxacin [52]. Therefore, there is a high likelihood that the bacterium detected in the feces was MDRP. This indicates that qRT-PCR method may also be applicable for rapid and highly sensitive monitoring of such MDRP.

The $P$. aeruginosa counts with qRT-PCR system closely reflected the treatment background of ICU patients. Specifically, the induction of abnormal proliferation of $P$. aeruginosa in the intestines was observed with the long-term use of various types of antibiotics. It has been shown that the eradication of $P$. aeruginosa is actually facilitated by discontinuing the administration of sulbactam/ampicillin, which is not active against $P$. aeruginosa $[53,54]$, or broad spectrum cephem antibiotics (cefepime), for which drug-resistant $P$. aeruginosa has low sensitivity [55]. The eradication of $P$. aeruginosa in the intestine was also observed after the withdrawal of mechanical ventilator use. Thus, we demonstrated that the timely monitoring of fecal $P$. aeruginosa accompanying medical interventions is possible with this system.

In this study, abnormal proliferation of $P$. aeruginosa in the intestines occurred in ICU patients with decreased obligate anaerobes in the intestines after antibiotic administration, and a negative correlation was observed between obligate anaerobe counts and $P$. aeruginosa in the intestines. A relationship has been shown between dysbiosis [56] and intestinal infection of $P$. aeruginosa in ICU patients. When the intestinal microbiota of ICU patients in whom ventilator-associated pneumonia occurred was analyzed using YIF-SCAN $\circledast$ [21-23], there was a dramatic decrease in the counts of obligate anaerobes, and dysbiosis was shown to have occurred $[30,57]$. We have also previously shown that dysbiosis is a high- 
risk factor for mortality in critically-ill ICU patients [58]. Moreover, Robak et al. showed that microbiotadependent IgA production is required for antibacterial immunity during acute bacterial pneumonia [59]. These findings indicate the importance of intestinal microbiota in ICU patients. Since both intestinal microbiota disturbances and $P$. aeruginosa infection dynamics can be understood simultaneously, the qRT-PCR method may be a very effective means of controlling the risk of infection in ICU patients.

There remain some limitations to our study. First, while we attempted to monitor drug-resistant $P$. aeruginosa with the concurrent use of 3 drug-resistance gene primers, $P$. aeruginosa has various other drug-resistance mechanisms. In the future, we anticipate that definitive diagnosis and monitoring of MDRP will also be possible with the generation of aminoglycoside resistance and new quinolone resistance gene detection primers. Second, horizontal transfer between multiple pathogens containing the $b / a_{\text {IMP }}$ gene has been reported; thus, the possibility that bacteria such as Enterobacteriaceae or Acinetobacter baumannii, which show carbapenem resistance, have the bla ${ }_{\mathrm{IMP}}$ gene cannot be ruled out. We think it will also be possible in the future to estimate gene origins by preparing detection primers for those genes and monitoring fluctuations in bacterial counts. Third, in the study of monitoring drug resistant $P$. aeruginosa in the feces of ICU patients, the sample size was small. Further studies with a larger sample size are necessary to clarify the relationship between the fluctuations of $P$. aeruginosa detected by qRT-PCR method and clinical course.

\section{Conclusion}

The features of this new $P$. aeruginosa quantification system based on 23S rRNA-targeted qRT-PCR are as follows: (1) it has very high specificity and sensitivity; (2) since it can quantify bacteria directly from clinical specimens, the time required for the measurement is about $6 \mathrm{~h}$, making early diagnosis of $P$. aeruginosa infection possible; (3) compared with conventional detection methods, the number of viable $P$. aeruginosa can be accurately determined in patients receiving antibiotics; and (4] the results obtained accurately reflect the various treatment backgrounds in ICU patients. The present study shows the potential of the method described herein as an effective tool for controlling nosocomial infections of $P$. aeruginosa as well as for judging the efficacy of antibiotic treatment and determining whether to continue or withdraw other medical actions.

\section{Abbreviations}

qRT-PCR: Quantitative reverse transcription PCR; ICU: Intensive care unit; MDRP: Multidrug-resistant $P$. aeruginosa; YIF-SCAN: Yakult Intestinal Flora-SCAN; CFU: Colony forming units; TSA: Trypticase soy agar; DAPI: 4', 6-diamidino-2-phenylindole; NCBI: National Center for Biotechnology Information; Ct. Threshold cycle; qPCR: Quantitative PCR; TSB: trypticase soy broth; DMEM: Dulbecco's modified Eagle's medium; FBS: Fetal bovine serum; IL-8; Interleukin-8; FISH: Fluorescence in situ hybridization

\section{Declarations}




\section{Ethics approval and consent to participate}

For experiments using human samples, all samples were anonymously coded in accordance with local ethical guidelines (as stipulated by the Declaration of Helsinki). Written informed consent was obtained from the patients and healthy volunteers. Approval was obtained from the Ethical Review Board of Osaka University for clinical samples (approved number: 09184-5) and from the Ethical Review Board of Yakult Central Institute for the samples from healthy adults (approved number: FY2017-025, FY2018-028).

\section{Consent for publication}

Not applicable.

\section{Availability of data and materials}

The datasets used and/or analyzed during the current study are available from the corresponding author on reasonable request.

\section{Competing interests}

The authors declare that they have no competing interests.

\section{Funding}

None.

\section{Author's contributions}

MN and SA carried out most of the experimental work and analyzed the data under the guidance of TA. AT contributed in vitro experiments using cell lines. TS analyzed data and performed statistical analysis. YK and AT contributed in vitro experiments using spiked samples. YK performed intestinal microbiota analysis. HT designed primers for sequencing 23S rRNA. KS and HO recruited subjects, collected clinical samples, and recorded clinical data. TA conceived and designed the experiments. NM and TA wrote the manuscript. All authors critically reviewed the manuscript.

\section{Acknowledgments}

We thank Yukihiro Yokoyama, MD for critical reading of the manuscripts. We also thank Hirotaka Haibara, Toshihiko Takada, and Ryoko liduka, for assistance with cell culture, FISH analyses, and 
cytokine assays, respectively.

\section{References}

1. Jones RN. Microbial etiologies of hospital-acquired bacterial pneumonia and ventilator-associated bacterial pneumonia. Clin Infect Dis. 2010;51(Suppl 1):81-7.

2. Fernández-Barat $L$, et al. Intensive care unit-acquired pneumonia due to Pseudomonas aeruginosa with and without multidrug resistance. J Infect. 2017;74[2]:142-52.

3. Newman JW, Floyd RV, Fothergill JL. The contribution of Pseudomonas aeruginosa virulence factors and host factors in the establishment of urinary tract infections. FEMS Microbiol Lett. 2017;364[15]:10.1093/femsle/fnx124.

4. Alexiou K, Drikos I, Terzopoulou M, Sikalias N, loannidis A, Economou N. A prospective randomised trial of isolated pathogens of surgical site infections [SSI]. Ann Med Surg [Lond]. 2017;21:25-9.

5. Aliyu S, Cohen B, Liu J, Larson E. Prevalence and risk factors for bloodstream infection present on hospital admission. J Infect Prev. 2018;19[1]:37-42.

6. Gellatly SL, Hancock RE. Pseudomonas aeruginosa: new insights into pathogenesis and host defenses. Pathog Dis. 2013;67[3]:159-73.

7. Kim HS, et al. Clinical characteristics and outcomes of Pseudomonas aeruginosa bacteremia in febrile neutropenic children and adolescents with the impact of antibiotic resistance: a retrospective study. BMC Infect Dis. 2017;17[1]:500.

8. Lodise TP Jr, et al. Predictors of 30-day mortality among patients with Pseudomonas aeruginosa bloodstream infections: impact of delayed appropriate antibiotic selection. Antimicrob Agents Chemother. 2007;51[10]:3510-5.

9. Tam VH, Chang KT, Abdelraouf K, et al. Prevalence, resistance mechanisms, and susceptibility of multidrug-resistant bloodstream isolates of Pseudomonas aeruginosa. Antimicrob Agents Chemother. 2010;54[3]:1160-4.

10. Horcajada JP, et al. Epidemiology and Treatment of Multidrug-Resistant and Extensively DrugResistant Pseudomonas aeruginosa Infections. Clin Microbiol Rev. 2019;32[4]:e00031-19.

11. Pang Z, Raudonis R, Glick BR, Lin TJ, Cheng Z. Antibiotic resistance in Pseudomonas aeruginosa: mechanisms and alternative therapeutic strategies. Biotechnol Adv. 2019;37[1]:177-92.

12. Micek ST, et al. An international multicenter retrospective study of Pseudomonas aeruginosa nosocomial pneumonia: impact of multidrug resistance. Crit Care. 2015;19[1]:219.

13. Martinez-Nadal G, et al. Inappropriate Empirical Antibiotic Treatment in High-risk Neutropenic Patients With Bacteremia in the Era of Multidrug Resistance. Clin Infect Dis. 2020;70[6]:1068-74.

14. Loonen AJ, Wolffs PF, Bruggeman CA, van den Brule AJ. Developments for improved diagnosis of bacterial bloodstream infections. Eur J Clin Microbiol Infect Dis. 2014;33[10]:1687-702.

15. Biondi EA, et al. Blood culture time to positivity in febrile infants with bacteremia. JAMA Pediatr. 2014;168[9]:844-9. 
16. Héry-Arnaud G, et al. Evaluation of quantitative PCR for early diagnosis of Pseudomonas aeruginosa infection in cystic fibrosis: a prospective cohort study. Clin Microbiol Infect. 2017;23[3]:203-7.

17. Scheer CS, et al. Impact of antibiotic administration on blood culture positivity at the beginning of sepsis: a prospective clinical cohort study. Clin Microbiol Infect. 2019;25[3]:326-31.

18. Kethireddy S, et al. Culture-Negative Septic Shock Compared With Culture-Positive Septic Shock: A Retrospective Cohort Study. Crit Care Med. 2018;46[4]:506-12.

19. Sakaguchi $S$, et al. Bacterial rRNA-targeted reverse transcription-PCR used to identify pathogens responsible for fever with neutropenia. J Clin Microbiol. 2010;48[5]:1624-8.

20. Van de Wyngaert Z, et al. Discontinuation of antimicrobial therapy in adult neutropenic haematology patients: A prospective cohort. Int J Antimicrob Agents. 2019;53[6]:781-8.

21. Matsuda K, Tsuji H, Asahara T, Kado Y, Nomoto K. Sensitive quantitative detection of commensal bacteria by rRNA-targeted reverse transcription-PCR. Appl Environ Microbiol. 2007;73[1]:32-9.

22. Matsuda K, Tsuji H, Asahara T, Matsumoto K, Takada T, Nomoto K. Establishment of an analytical system for the human fecal microbiota, based on reverse transcription-quantitative PCR targeting of multicopy rRNA molecules. Appl Environ Microbiol. 2009;75[7]:1961-9.

23. Kurakawa $\mathrm{T}$, et al. Development of a sensitive rRNA-targeted reverse transcription-quantitative polymerashain reaction for detection of Vibrio cholerae/mimicus, V. parahaemolyticus/alginolyticus and Campylobacter jejuni/coli. Microbiol Immunol. 2012;56[1]:10-20.

24. Jansen GJ, Wildeboer-Veloo AC, Tonk RH, Franks AH, Welling GW. Development and validation of an automated, microscopy-based method for enumeration of groups of intestinal bacteria. J Microbiol Methods. 1999;37(3):215-21.

25. Thompson JD, Gibson TJ, Plewniak F, Jeanmougin F, Higgins DG. The CLUSTAL_X windows interface: flexible strategies for multiple sequence alignment aided by quality analysis tools. Nucleic Acids Res. 1997;25(24):4876-82.

26. Matsuki T, et al. Quantitative PCR with 16S rRNA-gene-targeted species-specific primers for analysis of human intestinal bifidobacteria. Appl Environ Microbiol. 2004;70(1):167-73.

27. Jiang $M$, Zhang $F$, Wan $C$, et al. Evaluation of probiotic properties of Lactobacillus plantarum WLPL04 isolated from human breast milk. J Dairy Sci. 2016;99(3):1736-46.

28. Giribaldi $G$, et al. Involvement of inflammatory chemokines in survival of human monocytes fed with malarial pigment. Infect Immun. 2010;78(11):4912-21.

29. Takada T, Matsumoto K, Nomoto K. Development of multi-color FISH method for analysis of seven Bifidobacterium species in human feces. J Microbiol Methods. 2004;58(3):413-21.

30. Shimizu K, et al. Synbiotics modulate gut microbiota and reduce enteritis and ventilator-associated pneumonia in patients with sepsis: a randomized controlled trial. Crit Care. 2018;22(1):239.

31. Poirel L, Walsh TR, Cuvillier V, Nordmann P. Multiplex PCR for detection of acquired carbapenemase genes. Diagn Microbiol Infect Dis. 2011;70(1):119-23. 
32. Juan C, Moyá B, Pérez JL, Oliver A. Stepwise upregulation of the Pseudomonas aeruginosa chromosomal cephalosporinasonferring high-level beta-lactam resistance involves three AmpD homologues. Antimicrob Agents Chemother. 2006;50(5):1780-7.

33. Shu JC, et al. Interplay between mutational and horizontally acquired resistance mechanisms and its association with carbapenem resistance amongst extensively drug-resistant Pseudomonas aeruginosa (XDR-PA). Int J Antimicrob Agents. 2012;39(3):217-22.

34. Yokoyama Y, Miyake T, Kokuryo T, Asahara T, Nomoto K, Nagino M. Effect of Perioperative Synbiotic Treatment on Bacterial Translocation and Postoperative Infectious Complications after Pancreatoduodenectomy. Dig Surg. 2016;33(3):220-9.

35. Luna $\mathrm{CM}$, et al. Blood cultures have limited value in predicting severity of illness and as a diagnostic tool in ventilator-associated pneumonia. Chest. 1999;116(4):1075-84.

36. Opota O, Jaton K, Greub G. Microbial diagnosis of bloodstream infection: towards molecular diagnosis directly from blood. Clin Microbiol Infect. 2015;21(4):323-31.

37. Barsic B, Tambic A, Santini M, Klinar I, Kutlesa M, Krajinovic V. Antibiotic resistance among nosocomial isolates in a Croatian intensive care unit-results of a twelve-year focal surveillance of nosocomial infections. J Chemother. 2004;16(3):273-81.

38. Boyer A, et al. Pseudomonas aeruginosa acquisition on an intensive care unit: relationship between antibiotic selective pressure and patients' environment. Crit Care. 2011;15(1):R55.

39. Kraft R, Herndon DN, Finnerty CC, Cox RA, Song J, Jeschke MG. Predictive Value of IL-8 for Sepsis and Severe Infections After Burn Injury: A Clinical Study. Shock. 2015;43(3):222-7.

40. Anderson BJ, et al. Plasma sTNFR1 and IL8 for prognostic enrichment in sepsis trials: a prospective cohort study. Crit Care. 2019;23(1):400.

41. de Lima CD, et al. ExoU activates NF-KB and increases IL-8/KC sretion during Pseudomonas aeruginosa infection. PLoS One. 2012;7(7):e41772.

42. Cuzick A, Stirling FR, Lindsay SL, Evans TJ. The type III pseudomonal exotoxin U activates the c-Jun NH2-terminal kinase pathway and increases human epithelial interleukin-8 production. Infect Immun. 2006;74(7):4104-13.

43. Juan C, Peña C, Oliver A. Host and Pathogen Biomarkers for Severe Pseudomonas aeruginosa Infections. J Infect Dis. 2017;215(suppl_1):44-51.

44. Sawa T, Shimizu M, Moriyama K, Wiener-Kronish JP. Association between Pseudomonas aeruginosa type III secretion, antibiotic resistance, and clinical outcome: a review. Crit Care. 2014;18(6):668.

45. Narayanaswamy VP, et al. Novel Glycopolymer Eradicates Antibiotic- and CCCP-Induced Persister Cells in Pseudomonas aeruginosa. Front Microbiol. 2018;9:1724.

46. Li L, Mendis N, Trigui H, Oliver JD, Faucher SP. The importance of the viable but non-culturable state in human bacterial pathogens. Front Microbiol. 2014;5:258.

47. Cobos-Trigueros N, et al. Acquisition of Pseudomonas aeruginosa and its resistance phenotypes in critically ill medical patients: role of colonization pressure and antibiotic exposure. Crit Care. 
2015;19(1):218.

48. Li Y, Xia X, Li X, Xiao K, Zhuang X. Correlation between the use of antibiotics and development of a resistant bacterial infection in patients in the ICU. Biosci Trends. 2018;12(5):517-9.

49. Yusuf $E$, et al. Emergence of antimicrobial resistance to Pseudomonas aeruginosa in the intensive care unit: association with the duration of antibiotic exposure and mode of administration. Ann Intensive Care. 2017;7(1):72.

50. Ong DS, et al. Antibiotic exposure and resistance development in Pseudomonas aeruginosa and Enterobacter species in intensive care units. Crit Care Med. 2011;39(11):2458-63.

51. Kouda $S$, et al. Increased prevalence and clonal dissemination of multidrug-resistant Pseudomonas aeruginosa with the blalMP-1 gene cassette in Hiroshima. J Antimicrob Chemother. 2009;64(1):4651.

52. North DS, Fish DN, Redington JJ. Levofloxacin, a sond-generation fluoroquinolone. Pharmacotherapy. 1998;18(5):915-35.

53. Campoli-Richards DM, Brogden RN. Sulbactam/ampicillin. A review of its antibacterial activity, pharmacokinetic properties, and therapeutic use. Drugs. 1987;33(6):577-609.

54. Betrosian AP, Douzinas EE. Ampicillin-sulbactam: an update on the use of parenteral and oral forms in bacterial infections. Expert Opin Drug Metab Toxicol. 2009;5(9):1099-112.

55. Bassetti M, Vena A, Croxatto A, Righi E, Guery B. How to manage Pseudomonas aeruginosa infections. Drugs Context. 2018;7:212527.

56. Weiss GA, Hennet T. Mechanisms and consequences of intestinal dysbiosis. Cell Mol Life Sci. 2017;74(16):2959-77.

57. Hayakawa $\mathrm{M}$, et al. Dramatic changes of the gut flora immediately after severe and sudden insults. Dig Dis Sci. 2011;56(8):2361-5.

58. Shimizu K, et al. Probiotic/synbiotic therapy for treating critically ill patients from a gut microbiota perspective. Dig Dis Sci. 2013;58(1):23-32.

59. Robak $\mathrm{OH}$, et al. Antibiotic treatment-induced sondary IgA deficiency enhances susceptibility to Pseudomonas aeruginosa pneumonia. J Clin Invest. 2018;128(8):3535-45.

\section{Figures}



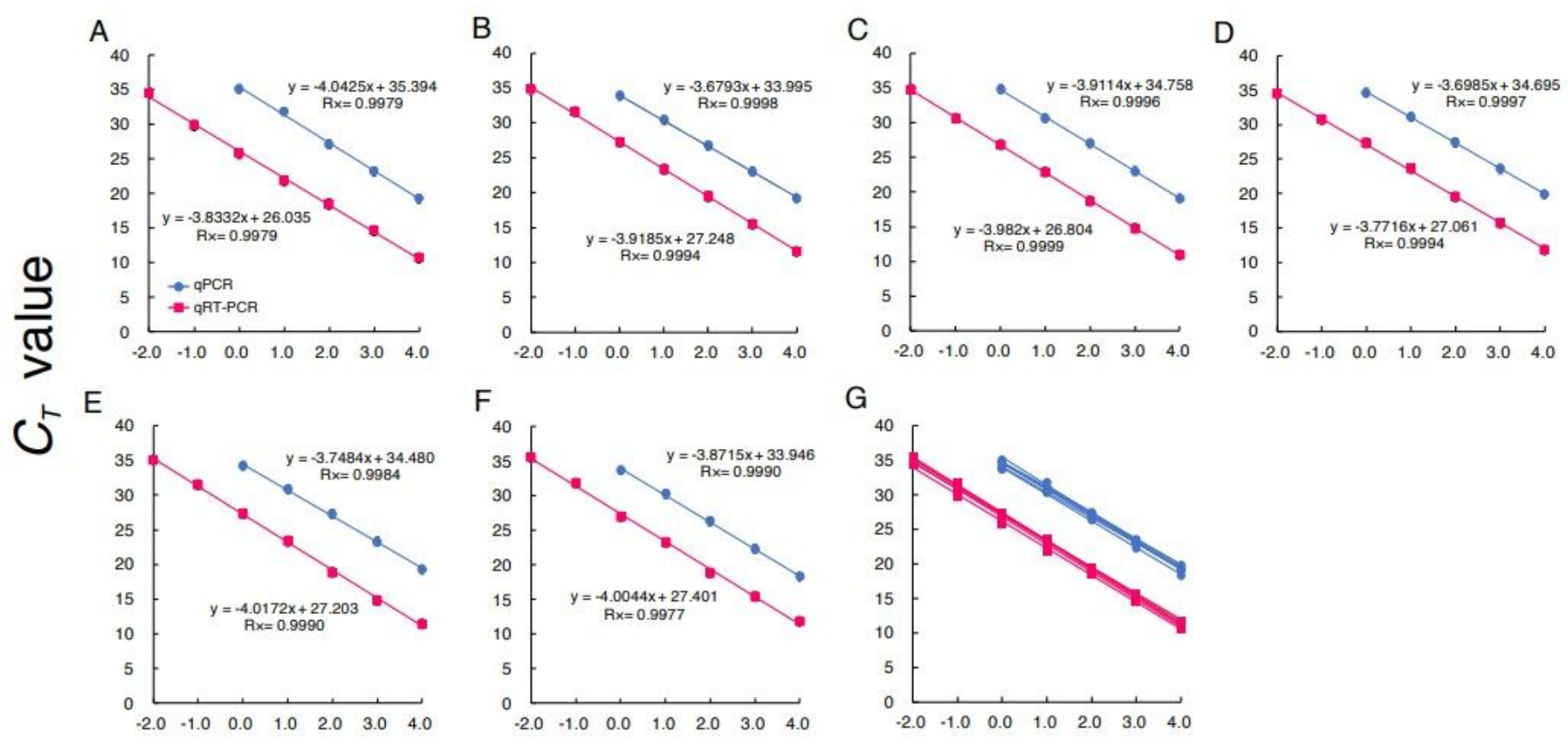

\section{$\log _{10}$ cells/reaction}

\section{Figure 1}

Specific quantification of cultured P. aeruginosa by qRT-PCR. P. aeruginosa ATCC 10145T (A), P. aeruginosa ATCC 9027 (B), P. aeruginosa ATCC 15442 (C), P. aeruginosa JCM 2776 (D), P. aeruginosa JCM 5961 (E), and P. aeruginosa DSM 6195 (F) were cultured separately in BHI broth. RNA and DNA were extracted from cultured samples in the early stationary phase. Bacterial counts were determined microscopically with DAPI staining. Based on bacterial counts, 10 -fold serial dilutions of RNA or DNA from 10-2 to 104 cells were assessed by qRT-PCR and qPCR assays, respectively. The CT values obtained were plotted against the log10 number of bacterial cells subjected to each reaction. Values are the mean \pm SEM. The experiments were conducted in triplicate. $(G)$ The parameters from the linear regression analyses for the 6 different $P$. aeruginosa strains. 

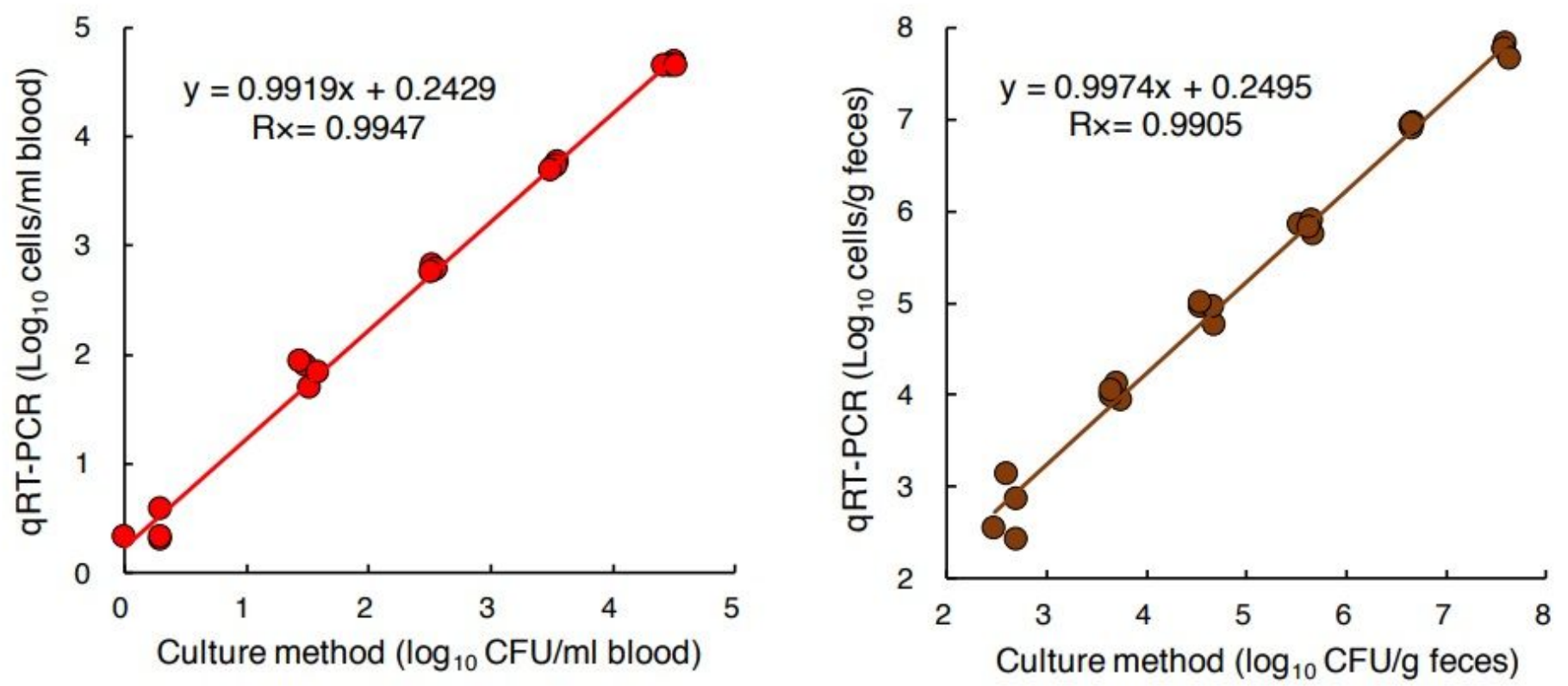

Figure 2

Quantification of P. aeruginosa spiked to human blood or feces using qRT-PCR and culture method. (A) Commercially available human peripheral blood was spiked with P. aeruginosa ATCC 10145T at final concentrations ranging from 100 to $104 \mathrm{cells} / \mathrm{ml}$. The total counts of P. aeruginosa were determined by qRT-PCR and the culture method. For qRT-PCR counts, the newly developed primer set for P. aeruginosa was used. For the culture method, an appropriate dilution series of each blood sample was cultured on NCC agar plates (selective medium for the quantification of P. aeruginosa). (B) Fecal samples collected from three individuals were spiked with serial dilutions of P. aeruginosa ATCC 10145T at final concentrations ranging from 102 to 107 cells/g feces and then assessed by qRT-PCR and the culture method as for the blood samples. The experiments were conducted in quadruplicate 


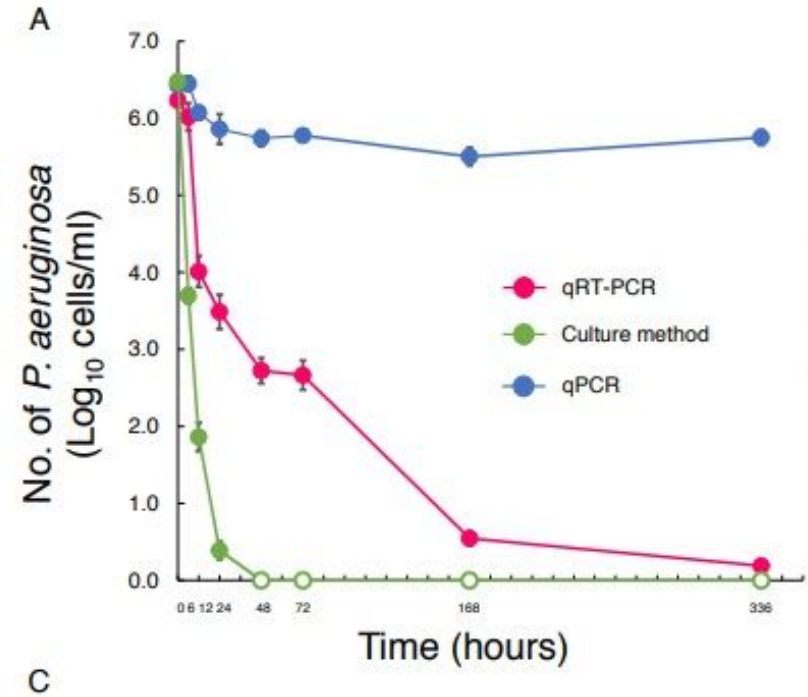

B
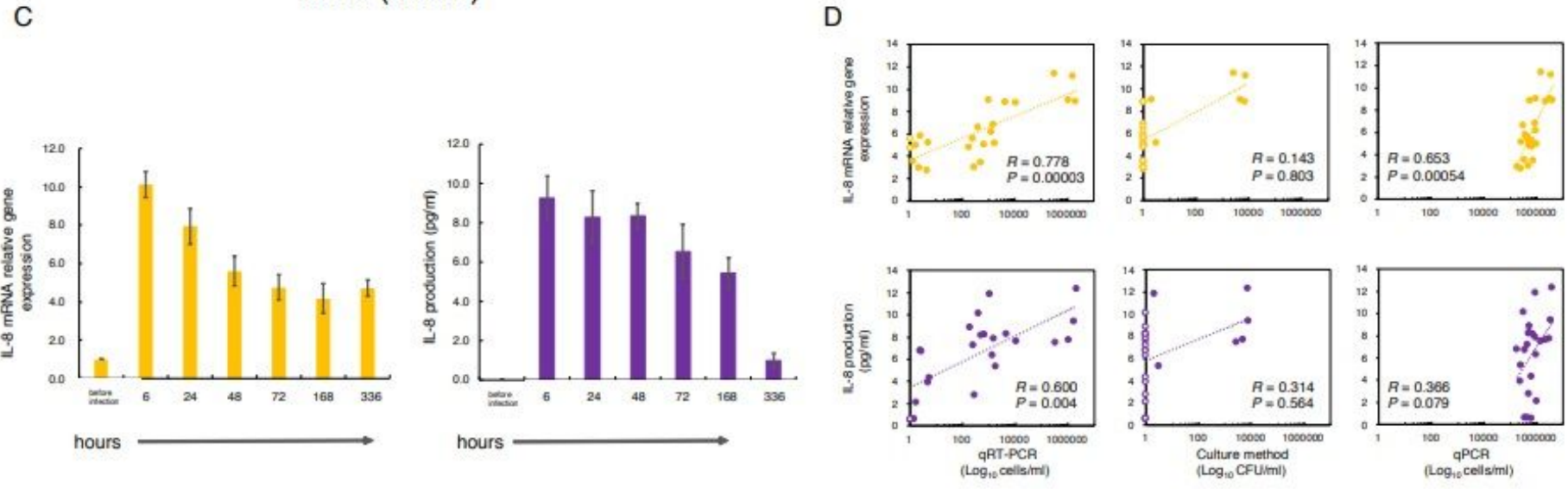

\section{Figure 3}

Comparison of detection methods in generating time-kill curves for MDRP exposed to antimicrobials. (A) Time-kill curves for P. aeruginosa ATCC BAA-2108TM exposed to colistin and doripenem combinations ( $\mathrm{n}$ $=4$ ). Bacterial counts in the culture solutions sampled over time were determined by qRT-PCR, culture method, and qPCR. For qRT-PCR and qPCR, the primer set targeting P. aeruginosa-specific 23S rRNA was used. For the culture method, the appropriate dilution series of cultures were cultured on TSA plates. (B) A part of the culture solutions sampled at 0,48 , and $336 \mathrm{~h}$ after cultivation were subjected to measurement of bacterial counts and assayed for FISH with FITC-labeled Eub338. Green and red images of P. aeruginosa were obtained by DAPI and FISH, respectively. Scale bars: $10 \mu \mathrm{m}$. (C) After Caco-2 cells were infected with a part of the culture solution used for determination of bacterial counts, relative amounts of IL-8-encoding transcripts were measured by qRT-PCR. Expression was normalized to GAPDH, and the relative gene expression values were compared to those of uninfected cells $(n=4)$. Also, the production of IL-8 was measured by ELISA $(n=4)$. (D) The relationship between P. aeruginosa counts by three different methods and the inflammatory response in infected Caco-2 cells were investigated. The upper diagram shows the correlation between the P. aeruginosa counts detected by qRT-PCR (left), culture method (center), and qPCR (right) and the relative mRNA expression of IL-8 in Caco-2 cells. The lower diagram shows the correlation between the P. aeruginosa counts and IL-8 production. Pearson's 
correlation coefficient was applied to the dataset. Data indicate the mean \pm SEM. When the bacterial count was not detected $(<1 \mathrm{cell} / \mathrm{ml})$, the plot was outlined in (A) and (D).
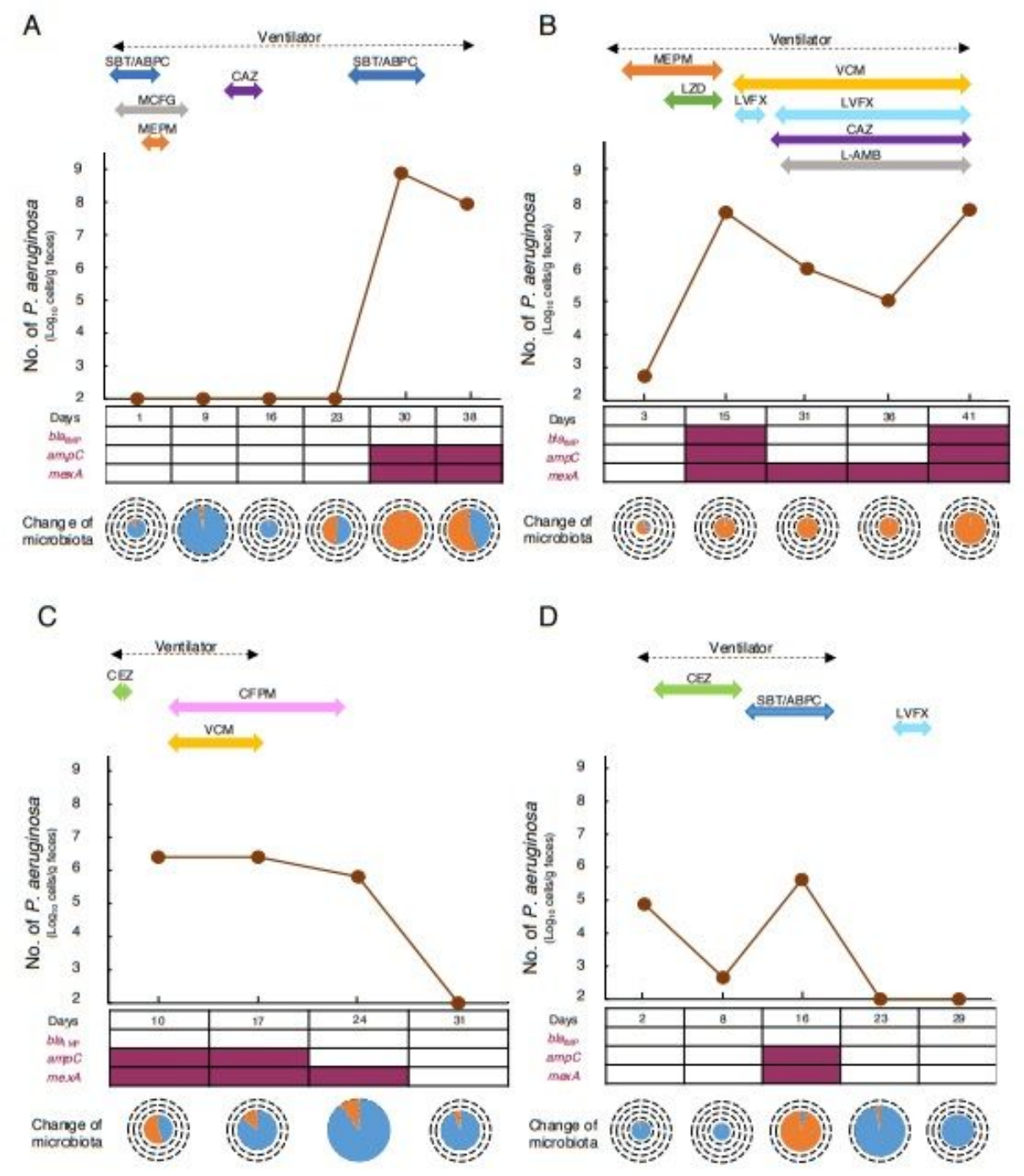

E

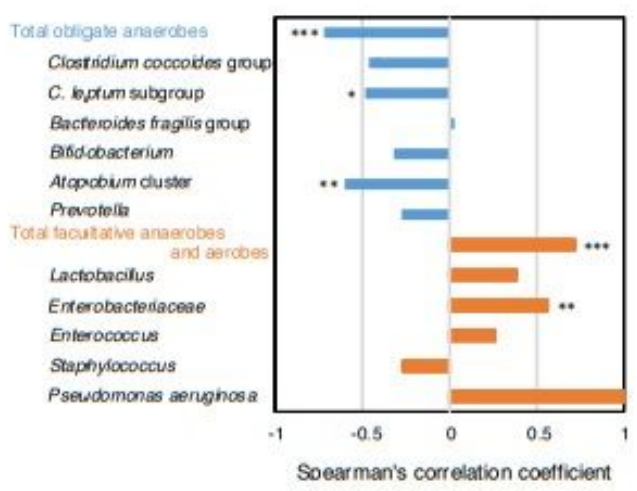

Figure 4

Monitoring of drug-resistant P. aeruginosa by qRT-PCR with the newly designed primer set reflects the clinical treatment. qRT-PCR quantification of P. aeruginosa using the P. aeruginosa-specific 23S rRNA primer set (brown) and simultaneous detection of drug resistance genes (blalMP, ampC, mexA) using 
drug resistance gene amplification primers (+, dark red-square; -, white-square) in fecal samples from 4 ICU patients (A-D). The abscissa of each graph represents the days of hospital stay. The microbiota composition was analyzed using the YIF-SCAN version of a 16S and 23S rRNA-targeted qRT-PCR system. The size of the pie charts shows the total bacterial counts (Circles indicate 1011, 1010, 109, 108, and 107 cells/g feces in this order from the outside to the inside), the color of the pie charts shows the percentage of obligate anaerobes (blue) and facultative anaerobes and aerobes (orange). The duration of ventilator use is indicated by a broken black line, and the duration of antibiotic use during the hospital stay is indicated by the various colored solid lines. (E) Association between the number of P. aeruginosa and fecal occupation rate of representative microorganisms. Spearman's rank correlation coefficient was applied to the dataset. $* P<0.05, * \star P<0.01, * \star * P<0.001$. SBT/ABPC, sulbactam/ampicillin; MCFG, micafungin; MEPM, meropenem; LZD, linezolid; VCM, vancomycin; LVFX, levofloxacin; CEZ, cefazolin; CAZ, ceftazidime; CFPM, cefepime; L-AMB, amphotericin B

\section{Supplementary Files}

This is a list of supplementary files associated with this preprint. Click to download.

- CritCareAAdditionalfile3.pdf

- CritCareAdditionalfile2.pdf

- CritCareAdditionalfile1.pdf 